\section{The Lyrid Meteors.}

Though in the present year the light of the full moon will impede abservations of these meteors, yet it is not improbable that the shower will be sufficiently strong to manifest its presence, provided that the atmospheric conditions prove favourable for the occasion. In 1905 the calculated maximum will fall on the night of April 19, as was the case last year, when Lyrids were found to be somewhat more numerous at Utrecht on the night of April ig than on the succeeding night, both nights having been clear; observations at Dublin, made, however, under less favourable conditions, tended also to confirm this result.

On the present occasion the shower will extend throughout the night of April I9, and of its three constituent maxima two at least will be visible to Cisatlantic observers. The calculated time of the first of these maxima is April rg, I $1 \mathrm{~h} .15 \mathrm{~m}$. G.M.T., while the second occurs at $15 \mathrm{~h}$.; the third may occur shortly after I4h., but owing to an uncertainty respecting some of the data requisite for its calculation, it is liable to arrive two or three hours later,
Dr. Nordenskjöld sailed from Buenos Aires on Christmas Eve, r9or, with the Swedish expedition. The object of the expedition was not to make a dash for the Pole, but, in conjunction with the English, Scottish, and German expeditions, to pursue certain scientific studies in the unknown Antarctic, the special sphere of operations being that section known as the Weddell Quadrant. Dr. Nordenskjöld appears to have succeeded in carrying out much of his programme, although he was unable to push far south, indeed, not so far as the Antarctic Circle, and notwithstanding disasters and hardships without a parallel in the history of Antarctic exploration.

The narrative is divided into two parts. The first, by Dr. Nordenskjöld himself, deals with the cruise of the Antarctic in the summer of I9OI-I902, and with the two consecutive winters spent on shore near Seymour Island. The second part is by Dr. Andersson and Capt. Larsen, and describes the attempt of the Antarctic to reach Nordenskiöld's winter quarters in

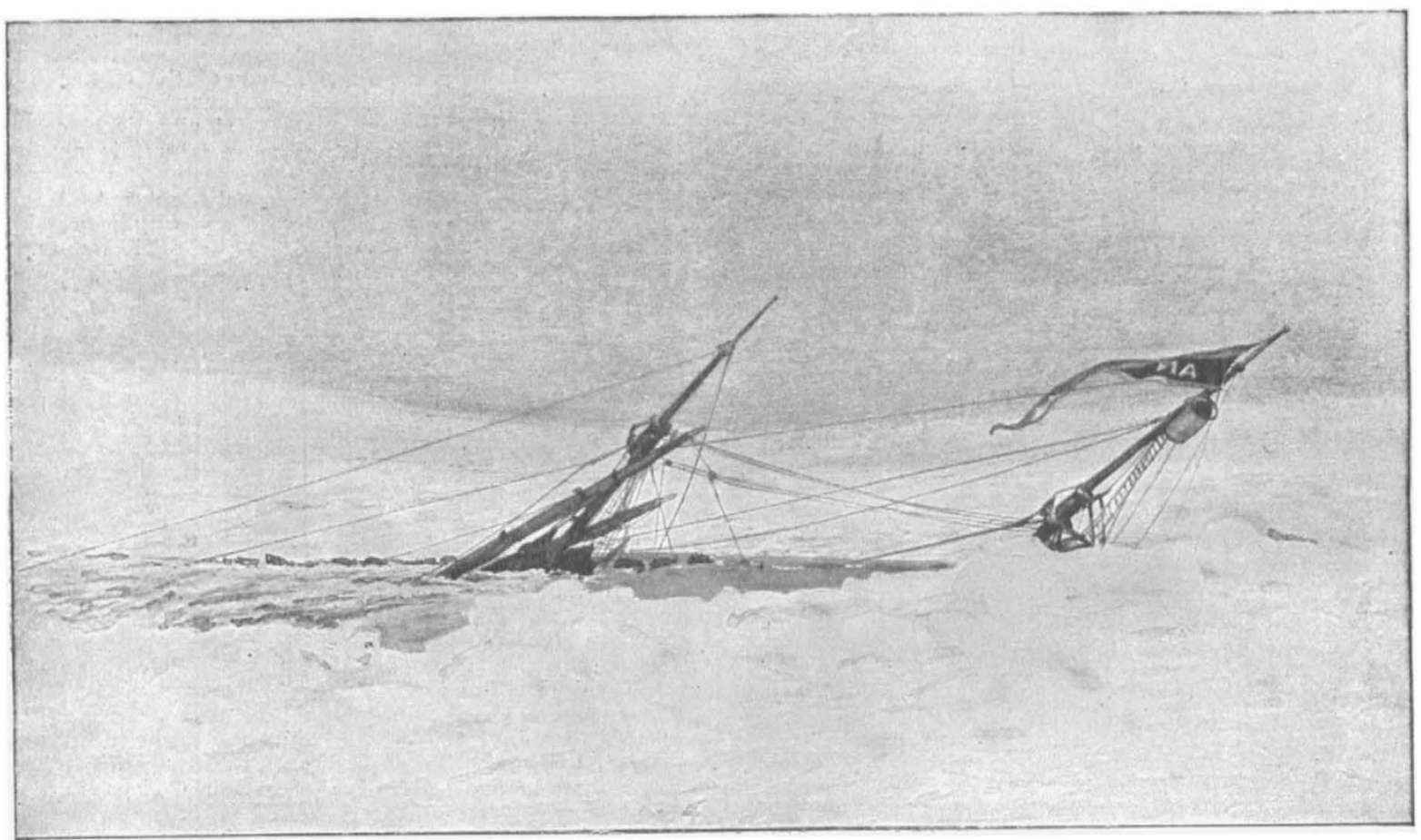

FIG. 1.-The loss of the Antarctic. From Nordenskjöld and Andersson's "Antarctica." The original illustration is slightly larger than the above.

and consequently elude the vigilance of observers of the first two maxima.

The conditions under which the anticipated display will take place indicate that it will be much above the average in brightness, and probably, notwithstanding the presence of the full moon, several brilliant meteors will be observed on April I9, owing to the meteoric concentration that characterises this night. John R. Henry.

\section{ANTARCTICA. ${ }^{1}$}

WE have entered upon a new era of South Polar literature, since each of the recent expeditions bears the promise and the potency of several books. Of these the recent publication of Dr. Otto Nordenskjöld's "Antarctica" is an addition to our knowledge of southern regions.

1 " Antarctica, or Two Years amongst the Ice of the South Pole." By Dr. N. Otto G. Nordenskjöld and Dr. Joh. Gunnar Andersson. Pp. xviii+608. (London: Hurst and Blackett, Ltd., rgo5.) Price r8s. net. the summer of $1902-1903$, and the loss of the ship in the ice-pack off Louis Philipp Land near the entrance of Erebus and Terror Gulf.

Geographically, the summer of I90I-I902 was perhaps the most prolific in discoveries. Louis Philipp Land was found to be continuous with Danco Land, and Gerlache Channel nothing but a continuation of D'Urville's Orleans Channel. Indeed, D'Urville is the real discoverer of the whole island. It appears that the Belgica maps of this locality present many difficulties and differences. The illustrations of this land from about lat. $63^{\circ} \mathrm{S}$. to $65^{\circ} \mathrm{S}$. bear a strong resemblance to Victoria Land, and seem as desolate and as heavily glaciated as land in lat. $75^{\circ} \mathrm{S}$. in the Ross Quadrant.

Continuing southwards down the east coast of King Oscar II. Land, the Antarctic was at last stopped by a perpendicular wall of ice about rzoft. high. This was in about the 66th degree of latitude south, and it grew clear to Dr. Nordenskjöld " that NO. I850, VOL. 7 I] 